Article

\title{
Sonic Hedgehog and TDP-43 Participate in the Spontaneous Locomotor Recovery in a Mouse Model of Spinal Motoneuron Disease
}

\author{
Rosario Gulino *, Rosalba Parenti and Massimo Gulisano \\ Department of Biomedical and Biotechnological Sciences, University of Catania, Via Santa Sofia 97, \\ 95123 Catania, Italy; parenti@unict.it (R.P.); m.gulisano@unict.it (M.G.) \\ * Correspondence: rogulino@unict.it; Tel.: +39-95-4781-320; Fax: +39-095-8993-111 \\ Academic Editor: Karin Pichler \\ Received: 28 December 2016; Accepted: 11 April 2017; Published: 19 April 2017
}

\begin{abstract}
Several studies have attempted to repair the damaged spinal cord (SC) by stimulating neurogenesis or neuroplasticity, with limited success. Sonic hedgehog (Shh) is involved in neural induction and stem cell functioning, but recent findings also suggest its role in regeneration and functional recovery. Transactive response DNA-binding protein of $43 \mathrm{kDa}$ (TDP-43) is a nuclear DNA/RNA binding protein involved in transcription and RNA processing. Recent findings have reported cytoplasmic inclusions containing TDP-43 in amyotrophic lateral sclerosis. Although substantial attention has been given to the toxic effects of this protein, the functional role of TDP-43 remains largely unclear. We used a mouse model of neurotoxic motoneuron depletion to study the role of the above-described factors in the compensatory changes occurring after the lesion. The injection of cholera toxin-B saporin into the gastrocnemius muscle caused a partial motoneuron death accompanied by an impairment of locomotion. Interestingly, motor activity was significantly restored as soon as one month later. Moreover, we observed an activity-dependent modification of Shh and synaptic proteins: synapsin-I and $\alpha$-amino-3-hydroxy-5-methyl-4-isoxazolepropionate (AMPA) receptors. Notably, the motor performance of lesioned animals correlated with the expression of synapsin-I and Shh. Conversely, the expression of Shh significantly correlated with the levels of synapsin-I, GluR2, and TDP-43. The results suggest that Shh and TDP-43 are crucial parts of a complex mechanism of neuroplasticity in a mouse model of SC motoneuron disease.
\end{abstract}

Keywords: motoneuron death; Sonic hedgehog; TDP-43; synaptic plasticity; spinal cord; recovery; mouse

\section{Introduction}

An emerging approach to central nervous system (CNS) repair after injury or neurodegeneration involves the activation of endogenous neural stem/precursor cells (NSCs/NPCs). Multipotent NSCs/NPCs are also present in the mammalian spinal cord (SC) [1,2] and they can be mobilized after SC injury (SCI), although their ability to generate neurons appears limited [2-4].

Another process that could be responsible for functional recovery after SCI is synaptic plasticity [5,6]. Previous studies in our laboratory have shown some mechanisms of SC plasticity in a mouse model of motoneuron depletion induced by intramuscular injection of the retrogradely transported, ribosome-inactivating toxin, cholera toxin-B saporin (CTB-Sap) [7-12].

The molecular regulation of adult neurogenesis has been widely explored [13-15]. Among these, Sonic hedgehog (Shh) is particularly interesting: it is a secreted glycoprotein promoting proliferation of NPCs and their differentiation to neurons and oligodendrocytes, during both development and 
adulthood [16-18]; moreover, emerging evidences suggest that it could be involved in synaptic plasticity [10,19-21].

Transactive response DNA-binding protein of $43 \mathrm{kDa}$ (TDP-43) is a nuclear DNA/RNA-binding protein involved in transcription and RNA processing [22-24]. TDP-43 was identified in the cytoplasmic inclusions typically observed in neurons and glial cells in amyotrophic lateral sclerosis (ALS), frontotemporal lobar degeneration, and Alzheimer disease $[23,25,26]$. Therefore TDP-43 aggregates could have toxic effects on motoneurons, however, other studies have associated some effects on motoneurons to the loss of function of theTDP-43 [23,27-29]. For instance, it has been found that TDP-43 could be localized in the synapses, likely affecting the local RNA translation and acting as a neuronal activity-responsive factor [30,31]. Interestingly, TDP-43 could also have a role in the motoneuron synaptic function and plasticity [28,32-34].

Here, we sought to analyze the role of Shh and TDP-43 in modulating the SC plasticity in a mouse model of motoneuron degeneration obtained by CTB-Sap injection. In this model, the involvement of TDP-43 is particularly attractive, given the described role in neurodegenerative diseases including ALS. Moreover, given that Shh is known to regulate NSCs/NPCs function and SC plasticity $[10,19,20]$, we wanted to test the hypothesis that Shh and TDP-43 could cooperate in modulating the spontaneous SC plasticity and the subsequent functional recovery after a partial removal of lumbar motoneurons. The worsening and the subsequent recovery of locomotion were evaluated after neurotoxic lesion, in relation to the expression levels of Shh and TDP-43. The results showed that the expression of synaptic proteins and Shh are linked to that of TDP-43. Moreover, their expression is activity-dependent and linked to the locomotor performance of lesioned animals.

\section{Materials and Methods}

Young adult male mice $(n=40)$ (Charles River, Strain 129, 5 weeks old) were used. Animal care and handling were done in accordance with the EU Directive 2010/63/EU, as well as with the Italian law D.lgs. 26/2014. All efforts were made to minimize the number of animals used and their suffering. Surgical procedures were performed under deep anesthesia where necessary (isoflurane).

\subsection{Neurotoxin-Induced Motoneuron Depletion}

Motoneuron depletion was induced by injection of CTB-Sap (Advanced Targeting Systems, San Diego, CA, USA) into the medial and lateral gastrocnemius muscles $(3.0 \mu \mathrm{g} / 3.0 \mu \mathrm{L}$ per muscle), as previously described [10]. After the bilateral injection of the toxin, mice were allowed to survive for either one week (LES-1wk, $n=9$ ) or one month (LES-1mo, $n=9$ ). Sham-lesioned animals received an equal dose of CTB-only vehicle, and they were then sacrificed at the same time-points as lesioned ones (SHAM-1wk, $n=4$; SHAM-1mo, $n=4$ ). In order to perform the histological evaluation of the effects of CTB-Sap, eight mice were injected unilaterally and then sacrificed at either one week $(n=4)$ or one month $(n=4)$ after the lesion. Finally, a group of intact mice were used as normal controls for western blot experiments (NC; $n=6)$.

\subsection{Grid Walk Test}

All animals, except the unilaterally lesioned ones, were subjected to grid walk test to evaluate motor activity after neurotoxic lesion. All tests were performed blind to animal treatments, starting the day before lesion, and then repeated at one week and at one month after toxin injection. Mice had to walk across a 50-cm long runway made of round metal bars placed at variable distance and moved at every trial to prevent habituation. The animals had to cross the runway three times per session. The number of footfalls relative to both hindlimbs at every crossing of the runway were counted and divided by the corresponding number of steps. Then, we calculated the mean values between test repetitions. 


\subsection{Immunohistochemical Analyses and Microscopy}

Unilaterally CTB-Sap injected animals were perfused transcardially with phosphate-buffered $4 \%$ paraformaldehyde. The lumbar SCs were dissected out, post-fixed for $1 \mathrm{~h}$, and then soaked overnight in a phosphate-buffered $20 \%$ sucrose solution at $4{ }^{\circ} \mathrm{C}$. Then, $20-\mu \mathrm{m}$-thick horizontal sections were cut on a freezing microtome and immunostained by using the following primary antibodies: mouse anti-ChAT (Immunological Sciences, Roma, Italy; Cat. No. MAB10838; Dilution 1:400); rabbit anti-synapsin-I (Abcam plc, Cambridge, UK; Cat. No. AB18814; Dilution 1:600), or goat anti-Shh (Santa Cruz Biotechnology Inc., Dallas, TX, USA; Cat. No. sc-1194; Dilution 1:200). Briefly, sections were mounted on gelatin-coated slides, incubated for $1 \mathrm{~h}$ in $5 \%$ normal donkey serum and $0.3 \%$ Triton X100 in PBS, and then overnight at $+4{ }^{\circ} \mathrm{C}$ with the primary antibody solution containing $0.2 \%$ Triton X100 and $2 \%$ normal donkey serum. Sections were then rinsed in PBS and incubated for $1 \mathrm{~h}$ with the appropriate Alexa Fluor 488 or 568 donkey anti-mouse, anti-rabbit, or anti-goat secondary antibodies (Thermo Fisher, Waltham, MA, USA; dilution 1:1000), in PBS plus 2\% normal donkey serum and $0.2 \%$ Triton X100. Then, sections were washed in PBS and counterstained for 5 min with DAPI (Life Technologies, dilution 1:20,000) in PBS. Negative controls were made by omitting the primary antibody. Slides were coverslipped with Permafluor (Thermo Fisher) and stored at $4{ }^{\circ} \mathrm{C}$ in the dark. Other series of sections were stained with cresyl violet, dehydrated, and mounted on slides. The imaging of stained sections was carried out by means of bright field optical microscope or laser confocal microscope (Leica Microsystems S.p.A., Milano, Italy).

\subsection{Western Blotting Quantification}

After the last grid walk test session, bilaterally lesioned animals were sacrificed by decapitation. Lumbar SCs were dissected out and homogenized. Proteins (20 $\mathrm{\mu g} /$ sample) were separated on a $4-20 \%$ polyacrylamide gel and transferred to a nitrocellulose membrane. After blocking for $1 \mathrm{~h}$ with $5 \%$ non-fat dry milk, membranes were incubated for $2 \mathrm{~h}$ with one of the following primary antibodies: mouse anti-ChAT (Immunological Sciences Cat. No. MAB10838; Dilution 1:400), rabbit anti-synapsin-I (Abcam plc, Cat. No. AB18814; Dilution 1:1000), goat anti-Shh (Santa Cruz Biotechnology Inc., Cat. No. sc-1194; Dilution 1:500), goat anti-GluR2 (Santa Cruz Biotechnology Inc., Cat. No. sc-7610; Dilution 1:300), and rabbit anti-TDP43 (Cell Signaling, Danvers, MA, USA; Cat. No. 3449; Dilution 1:1000). Then, membranes were washed and incubated for $1 \mathrm{~h}$ with the appropriate peroxidase-conjugate goat anti-rabbit (Thermo Fisher; Cat. No. 1858415; Dilution 1:6000), goat anti-mouse (Thermo Fisher; Cat. No. 1858413; Dilution 1:6000), or rabbit anti-goat (Merck Millipore, Vimodrone, Italy; Cat. No. AP106P; Dilution 1:10,000) secondary antibodies. Peroxidase activity was developed by enhanced chemiluminescent substrate (Thermo Fisher; Cat. No. 34075) and acquired by an Uvitec Alliance LD2 (Uvitec, Cambridge, UK). Then, the protocol was repeated for quantification of actin, using a mouse anti-actin primary antibody (Merck Millipore, Cat. No. MAB1501; Dilution 1:700) followed by a goat anti-mouse secondary antibody (Thermo Fisher, Cat. No. 1858413; Dilution 1:5000). Digitalized grayscale images were used for optical density measurement by using ImageJ software. Density values were normalized to actin levels measured in the same membrane. All assays were performed in triplicate.

\subsection{Statistical Analysis}

Differences between lesioned and control groups in grid walk test and western blot data were evaluated by one-way ANOVA followed by Tukey's post-hoc test.

In order to assess whether the motor performance could depend on the expression levels of the analyzed proteins, we performed linear regression and correlation. The same tests were used to verify if the expression levels of proteins were correlated with each other. $p$ values of at least $<0.05$ were considered to be significant.

All analyses were performed by means of Systat 12 (Systat Software Inc., San Jose, CA, USA). 


\section{Results}

All animals survived surgery, but two mice, belonging to the LES-1mo and SHAM-1wk groups, respectively, were excluded from the study due to surgical complications. Soon after CTB-Sap injection (2-3 days), mice showed a significant weakness of the hindlimbs, although they were still able to perform functional tests. Sham lesioned and normal groups did not differ from each other in terms of motor performance and western blot data. Therefore, these groups were pooled together in a single control group (CTRL).

\subsection{Neurotoxic Motoneuron Depletion}

The analysis of cresyl violet stained (Figure 1A,B) SC sections belonging to the unilaterally lesioned LES-1wk group demonstrated an evident motoneuron loss within the lumbar SC ventral horn (L4-L5 segments) ipsilaterally to the injected muscles (Figure 1B), as compared to the contralateral side (Figure 1A). The observed motoneuron depletion (about 35\%, as estimated by counting cresyl-violet stained motoneuron profiles in four horizontal sections per animal) was similar at one month after the lesion, as shown previously [21].

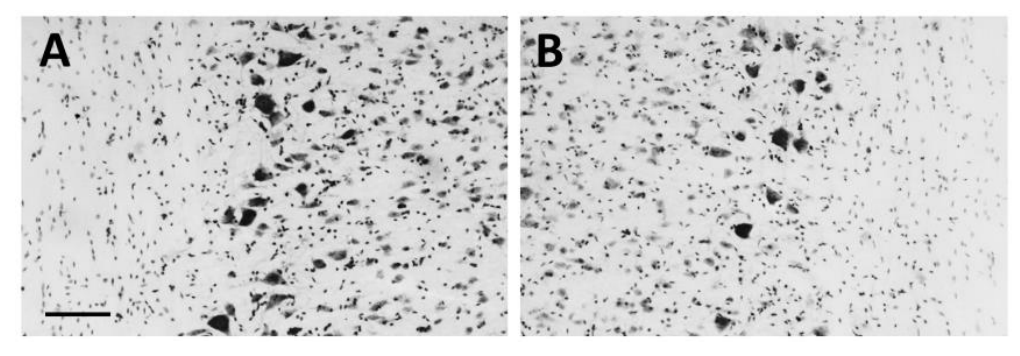

Figure 1. Cresyl violet staining. The motoneuron depletion is evident in the cholera toxin-B saporin (CTB-Sap) injected side (B) compared to the intact side (A). Scale bar: $100 \mu \mathrm{m}$.

\subsection{Locomotor Activity after CTB-Sap Lesion}

The neurotoxic lesion significantly affected the motor performance at the grid walk test (one-way ANOVA: $p<0.001$; Figure 2). In particular, one week after the lesion, lesioned animals showed a five-fold increase of the number of footfalls/step (Tukey's post-hoc test: $p<0.001$; Figure 2). Interestingly, one month after the lesion, mice showed a significant 3.5-fold reduction of the number of errors (Tukey's post-hoc test: $p<0.001$; Figure 2), thus reaching a motor performance similar to control levels (Tukey's post-hoc test: $p>0.05$; Figure 2).

\section{Grid walk - Footfalls/step}

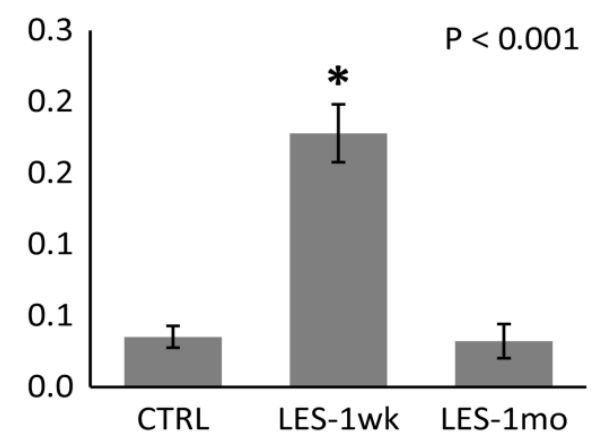

Figure 2. Motor performance scored at the grid walk test. A dramatic worsening of performance occurred after lesion, as shown by a five-fold increase of footfalls at one week, but it was followed by a complete recovery at one month after the lesion. CTRL: control; LES-1wk: one week post-lesion; LES-1mo: one month post-lesion. The asterisk indicates significant difference from the other groups. 


\subsection{Protein Expression after CTB-Sap Lesion}

The analysis of western blot data revealed a significant (one-way ANOVA: $p<0.05$; Figure 3A) $24 \pm 6 \%$ decrease of the average ChAT expression at one week after the lesion (Tukey's post-hoc test: $p<0.05$; Figure 3A), which was restored to near-normal levels at one month (Tukey's post-hoc test: $p>0.05$; Figure 3A). Similarly, the mean expression levels of synapsin-I in the lumbar SC decreased by $33 \pm 4 \%$ at one week (one-way ANOVA: $p<0.001$; Tukey's post-hoc test: $p<0.01$; Figure 3B) and appeared similar to control levels at one month after the lesion (Tukey's post-hoc test: $p>0.05$; Figure 3B). Moreover, the average levels of Shh at one week after the lesion showed a small but significant decrease (one-way ANOVA: $p<0.05$; Tukey's post-hoc test: $p<0.05$; Figure $3 C$ ) by $8 \pm 3 \%$, which significantly increased at one month (Tukey's post-hoc test: $p<0.05$; Figure 3C). Western blot data were confirmed by immunofluorescence, showing an evident though transient decrease of ChAT, synapsin-I, and Shh at one week after the lesion (Figure 4). Conversely, the average expression levels of both GluR2 and TDP-43 were unaffected by the CTB-Sap lesion (One way ANOVA: $p>0.05$; Figure 3D,E).

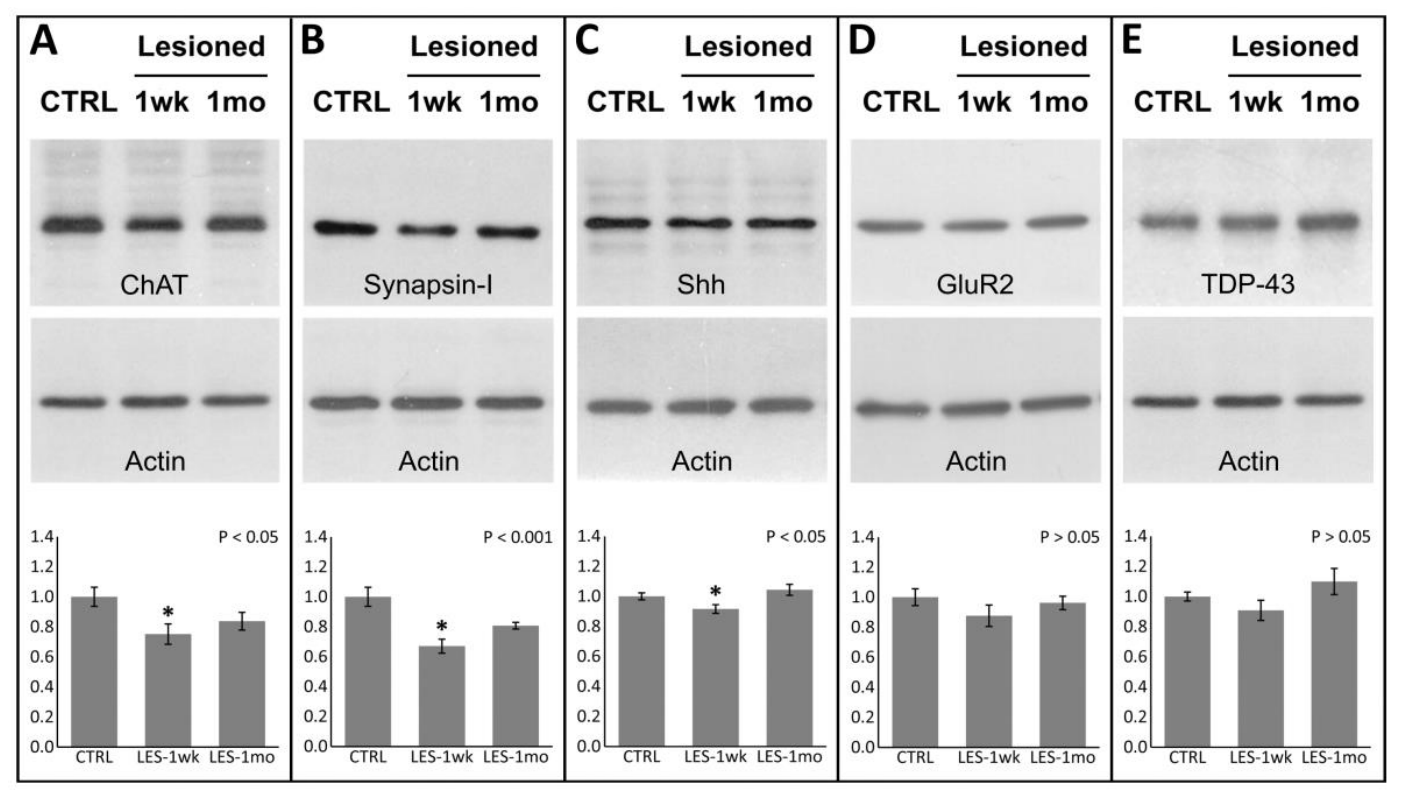

Figure 3. Protein quantification by western blotting. Expression levels of ChAT, synapsin-I, Sonic hedgehog (Shh), GluR2, and TDP-43 are measured and normalized to actin levels. A significant reduction of ChAT (A), synapsin-I (B), and Shh (C) was observed at one week after the lesion, as also confirmed by immunohistochemistry (Figure 4). At one month, the expression levels of these proteins returned to control levels (A-C), suggesting an activity-dependent regulation of their expression. The average expression levels of GluR2 and TDP-43 were not significantly modified after lesion (D,E). Asterisks indicate significant difference from control levels. $p$ values are reported in the graphs. The asterisk indicates significant difference from the other groups.

\subsection{Linkage between Protein Expression Levels and Motor Performance}

We sought to address the possibility that the worsening of functional performance after injury and/or the following recovery could be linked to the expression levels of the analyzed proteins in the lumbar SC. LES-1wk and LES-1mo groups were pooled together and the correlation between the functional performance at the grid walk test, as well as the expression levels of ChAT, synapsin-I, Shh, GluR2 and TDP-43 was carried out and the results are shown in Figure 5. Among the analyzed proteins, only synapsin-I ( $r=0.304 ; p<0.05$; Figure 5A) and Shh $(r=0.266 ; p<0.05$; Figure 5C) were significantly correlated with grid walk performance in the lesioned animals, and the higher their expression levels, the better their locomotor ability appeared. Conversely, no significant correlations were found within the control group (Figure 5B,D). 


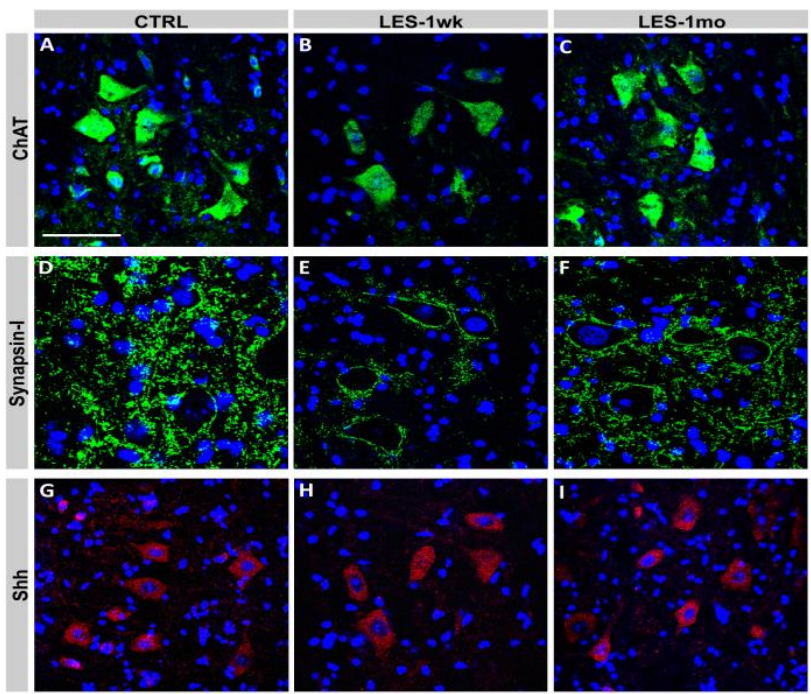

Figure 4. Immunohistochemical staining. The modifications of the expression levels of ChAT (A-C, green), synapsin-I (D-F, green), and Shh (G-I, red) already observed by western blotting have been confirmed by fluorescence immunohistochemistry and visualized by confocal microscopy. A reduction of protein expression, especially that of synapsin-I, is evident at one week after the lesion $(B, E, H)$, while a visible recovery occurred at one month $(\mathbf{C}, \mathbf{F}, \mathbf{I})$, as compared to the control levels $(\mathbf{A}, \mathbf{D}, \mathbf{G})$. Cell nuclei were counterstained with DAPI (blue). Scale bar: $50 \mu \mathrm{m}$ in A for (A-I).

LESIONED
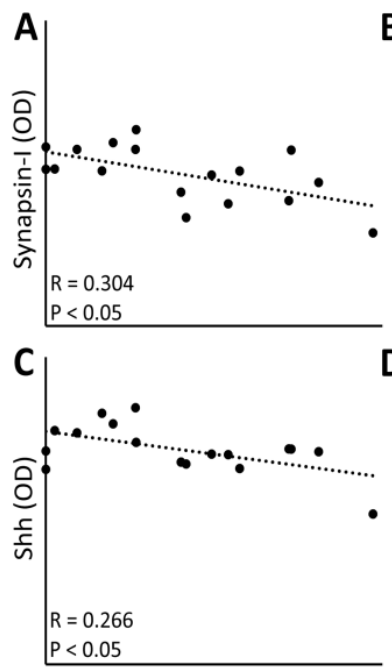

Grid walk (footfalls)

\section{CONTROLS}
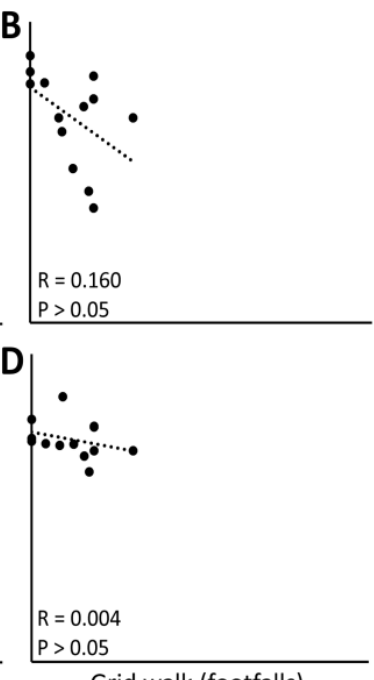

Grid walk (footfalls)

Figure 5. Linear regression and correlation. The number of footfalls at the grid walk test significantly correlate with the levels of synapsin-I and Shh measured in the lesioned spinal cord (SC) (A,C), but not with the expression levels in the intact SC (B,D). These data confirm an activity-dependent expression of these proteins in the SC after motoneuron removal and the subsequent recovery. OD: optical density. Each dot represents the values relative to each individual mouse. Dotted lines represent the trendlines.

Then, we verified if the analyzed proteins could be associated with each other. The results showed that the expression levels of synapsin-I correlates with both Shh $(r=0.402 ; p<0.01$; Figure 6A) and TDP-43 ( $r=0.241 ; p<0.05$; Figure 7C), and that Shh and TDP-43 strongly correlate with each other $(r=0.627 ; p<0.001$; Figure $6 \mathrm{E})$, suggesting a role of both proteins in synaptic plasticity. Moreover, the expression levels of Shh correlate with those of GluR2 ( $r=0.335 ; p<0.01$; Figure $6 \mathrm{C})$, while the 
expression levels of TDP-43 also correlate with those of ChAT $(r=0.273 ; p<0.05$; Figure 7A). Again, all these correlations were significant only within the lesioned groups, whereas no associations between variables were found within the control group (Figure 6B,D,F and Figure 7B,D).

LESIONED
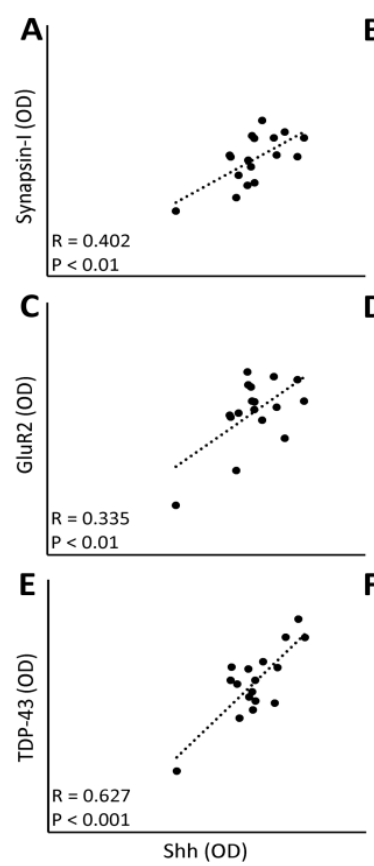

CONTROLS
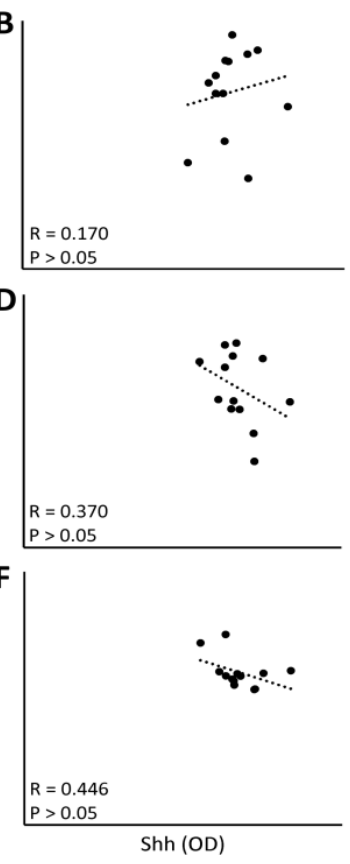

Figure 6. Linear regression and correlation between the expression levels of Shh and those of synapsin-I (A,B), GluR2 (C,D), and TDP-43 (E,F). Interestingly, the levels of Shh protein measured by western blotting strongly correlate with those of all other proteins in lesioned SCs $(\mathbf{A}, \mathbf{C}, \mathbf{E})$, but not in the intact group (B,D,F). OD: optical density. Each dot represents the expression levels in each individual mouse. Dotted lines represent the trendlines.

LESIONED

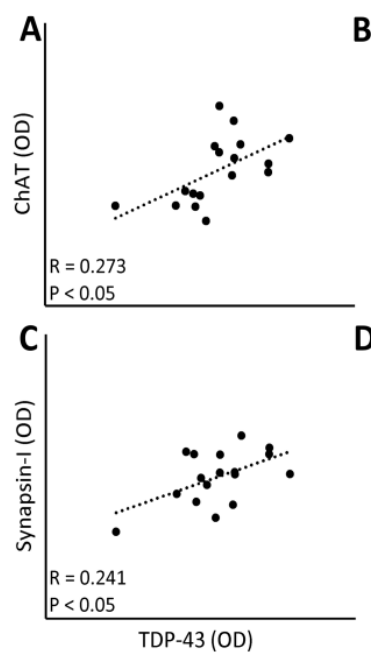

CONTROLS

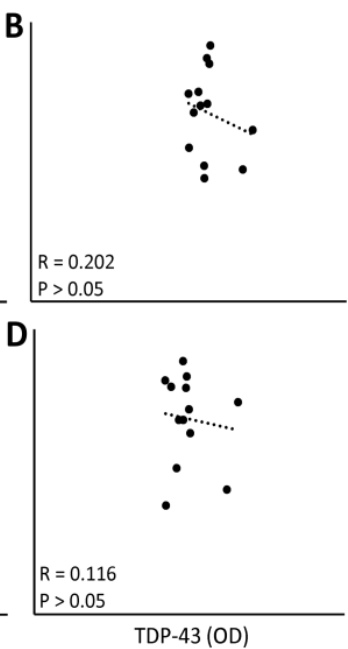

Figure 7. Linear regression and correlation between the expression levels of TDP-43 and those of ChAT (A,B) and synapsin-I (C,D). Notably, the levels of TDP-43 measured by western blotting strongly correlate with those of both proteins in the lesioned $(\mathbf{A}, \mathbf{C})$, but not in the intact (B,D) SCs. OD: optical density. Each dot represents the expression levels in each individual mouse. Dotted lines represent the trendlines. 


\section{Discussion}

In our previous studies [10,19-21], a neurotoxic model of SC motoneuron removal was developed in order to study the subsequent compensatory changes within the SC circuitry. The injection of CTB-Sap into the gastrocnemius muscle caused a partial motoneuron loss accompanied by the impairment of hindlimb function. The motoneuron depletion was accompanied by a decrease of ChAT expression within the lumbar SC at one week after the lesion. Given that the majority of acetylcholine release within the SC derives from the motoneuronal activity [35,36], it is expected that the observed downregulation of ChAT could be produced mainly by the motoneuron loss, and in part by the resulting disruption of spinal circuitry. One month after the lesion, the expression levels of ChAT were partially restored, probably as a result of the recovery of synaptic activity within the lumbar SC, which was accompanied by the improvement of motor performance, even though the motoneuron loss was permanent. Therefore, we can argue that the restoration of both ChAT expression and motor activity could be sustained by an increased activity of the spared motoneurons. Conversely, the increased motoneuron activity could probably be supported by an upregulation of synaptic efficacy within the surrounding spinal circuitry. This assumption is confirmed by the expression levels of synapsin-I in the lumbar SC, which decreased after lesion and then recovered, similarly to ChAT, at one month, in an activity-dependent fashion. In fact, synapsin-I is a synaptic vesicle protein whose synthesis and phosphorylation state have been linked to synaptic strength [37-39]. Similarly to ChAT and synapsin-I, Shh expression was downregulated at one week after the lesion and then restored at one month. This evidence suggests that the expression of these proteins could be activity-dependent and probably linked to a compensatory increase of neuronal activity after neurotoxic cell death and the consequent disruption of SC circuitry. The activity-dependent regulation of synapsin-I and Shh was confirmed by the correlation of their expression levels with the grid walk performance. The involvement of synapsin-I in functional recovery after SCI is well-known and it has been previously shown also in our lab, in models of both neurotoxic or traumatic SCI $[6,10,40]$. On the other hand, the role of Shh in synaptic plasticity is relatively novel and preliminary evidence from other studies have previously been provided by us $[10,19]$. Functional studies are still ongoing to confirm this hypothesis. Here, the involvement of Shh in synaptic plasticity was also suggested by its correlation with the expression levels of both synapsin-I and GluR2, which have pre- and post-synaptic roles in synaptic plasticity, respectively. Along with that of synapsin-I, the role of the AMPA receptor subunits in synaptic plasticity is important. In particular, it is known that the regulation of the calcium-permeable AMPA receptors is crucial for synaptic efficacy, and that the ion permeation is dependent on the amount of Q/R-unedited GluR2 subunits included in the AMPA channels [41,42]. For these reasons, the correlation with GluR2 subunit expression, observed in lesioned but not control animals, is noteworthy. Moreover, it is known that motoneurons in ALS have cytoplasmic inclusions of TDP-43 together with downregulation of the ADAR2 enzyme [27], with consequent alterations of GluR2 editing that make neurons more vulnerable to excitotoxic damage in ALS [43].

Moreover, the expression levels of ChAT, synapsin-I, and Shh correlate with those of TDP-43. This finding is novel and promising for a couple of reasons: for instance, it has been recently found that TDP-43 modulates the local translation of mRNAs at the synapse, thus participating in a complex regulation of synaptic strength $[30,31]$. Moreover, other recent findings have proven that the depletion of TDP-43 could cause locomotor deficits in Drosophila by affecting the synaptic function [28,32]. Interestingly, Shh seems to impact on synaptic plasticity by similar mechanisms, including the modification of the presynaptic terminal size, synaptic vesicle size, and postsynaptic currents $[10,19,20,44]$. Therefore, the strong correlation found between Shh and TDP-43 proteins could be due to a functional association, which requires a deeper investigation. It is noteworthy that this association is present only after lesion, although it is absent in normal conditions. The results together suggest differential roles of these proteins in the SC, in either physiological or pathological conditions.

Interestingly, as observed in our previous studies [10,21], a moderate cell proliferation occurred in the same SC area where neurotoxic removal of motoneurons took place. Double staining 
immunohistochemical studies have shown that virtually all of these proliferating cells were Glial Fibrillary Acidic Protein (GFAP)-positive astrocytes [10,21]. Glial reaction is a common response to tissue damage in the CNS [45,46], and our results indicate that this reaction could also occur after the neurotoxic degeneration of motoneuron, although its extent was limited, as demonstrated by the lack of GFAP increase in the lumbar SC after CTB-Sap lesion [21].

\section{Conclusions}

As previously mentioned, Shh is an important regulator of adult neurogenesis [16,18], so it is reasonable to assume that the observed downregulation of Shh could affect the glial reaction. It is therefore expected that an experimental overexpression of Shh signaling in the SC could increase NPCs proliferation, reduce glial reaction, and remove some of the factors that prevent neurogenesis. Moreover, the assumed participation of this factor in SC plasticity could be expected to result in multiple positive effects of such treatment to functional recovery. Given the increasing interest in TDP-43 in regards to several neurodegenerative diseases, including ALS [47,48], we believe that the elucidation of its physiological role in the SC would provide an important contribution. Moreover, we believe that further efforts to achieve SC repair by stimulating the intrinsic plastic potential of SC circuitries will produce interesting results.

Acknowledgments: This work was funded by the Italian Ministry of Education, University and Research.

Author Contributions: Rosario Gulino and Massimo Gulisano conceived, designed, and performed the experiments; Rosario Gulino and Rosalba Parenti analyzed the data; Rosario Gulino, Rosalba Parenti, and Massimo Gulisano contributed reagents and materials/analysis tools; Rosario Gulino wrote the paper; Rosalba Parenti and Massimo Gulisano contributed to the final version of the manuscript.

Conflicts of Interest: The authors declare no conflict of interest.

\section{References}

1. Horner, P.J.; Power, A.E.; Kempermann, G.; Kuhn, H.G.; Palmer, T.D.; Winkler, J.; Thal, L.J.; Gage, F.H. Proliferation and differentiation of progenitor cells throughout the intact adult rat spinal cord. J. Neurosci. 2000, 20, 2218-2228. [PubMed]

2. Weiss, S.; Dunne, C.; Hewson, J.; Wohl, C.; Wheatley, M.; Peterson, A.C.; Reynolds, B.A. Multipotent CNS stem cells are present in the adult mammalian spinal cord and ventricular neuroaxis. J. Neurosci. 1996, 16, 7599-7609. [PubMed]

3. Mothe, A.J.; Tator, C.H. Proliferation, migration, and differentiation of endogenous ependymal region stem/progenitor cells following minimal spinal cord injury in the adult rat. Neuroscience 2005, 131, 177-187. [CrossRef] [PubMed]

4. Yang, H.; Lu, P.; McKay, H.M.; Bernot, T.; Keirstead, H.; Steward, O.; Gage, F.H.; Edgerton, V.R.; Tuszynski, M.H. Endogenous neurogenesis replaces oligodendrocytes and astrocytes after primate spinal cord injury. J. Neurosci. 2006, 26, 2157-2166. [CrossRef] [PubMed]

5. Edgerton, V.R.; Tillakaratne, N.J.; Bigbee, A.J.; de Leon, R.D.; Roy, R.R. Plasticity of the spinal neural circuitry after injury. Ann. Rev. Neurosci. 2004, 27, 145-167. [CrossRef] [PubMed]

6. Gulino, R.; Dimartino, M.; Casabona, A.; Lombardo, S.A.; Perciavalle, V. Synaptic plasticity modulates the spontaneous recovery of locomotion after spinal cord hemisection. Neurosci. Res. 2007, 57, 148-156. [CrossRef] [PubMed]

7. Llewellyn-Smith, I.J.; Martin, C.L.; Arnolda, L.F.; Minson, J.B. Tracer-toxins: Cholera toxin B-saporin as a model. J. Neurosci. Methods 2000, 103, 83-90. [CrossRef]

8. Wiley, R.G.; Kline, R.H., IV. Neuronal lesioning with axonally transported toxins. J. Neurosci. Methods 2000, 103, 73-82. [CrossRef]

9. Fargo, K.N.; Sengelaub, D.R. Testosterone manipulation protects motoneurons from dendritic atrophy after contralateral motoneuron depletion. J. Compos. Neurol. 2004, 469, 96-106. [CrossRef] [PubMed]

10. Gulino, R.; Perciavalle, V.; Gulisano, M. Expression of cell fate determinants and plastic changes after neurotoxic lesion of adult mice spinal cord by cholera toxin-B saporin. Eur. J. Neurosci. 2010, 31, 1423-1434. [CrossRef] [PubMed] 
11. Gulino, R. Neuroplasticity and repair in rodent neurotoxic models of spinal motoneuron disease. Neural Plast. 2016, 2016. [CrossRef] [PubMed]

12. Gulino, R.; Litrico, L.; Leanza, G. Long-term survival and development of fetal ventral spinal grafts into the motoneuron-depleted rat spinal cord: Role of donor age. Brain Res. 2010, 1323, 41-47. [CrossRef] [PubMed]

13. Abrous, D.N.; Koehl, M.; Le Moal, M. Adult neurogenesis: From precursors to network and physiology. Physiol. Rev. 2005, 85, 523-569. [CrossRef] [PubMed]

14. Hagg, T. Molecular regulation of adult CNS neurogenesis: An integrated view. Trends Neurosci. 2005, 28, 589-595. [CrossRef] [PubMed]

15. Lledo, P.M.; Alonso, M.; Grubb, M.S. Adult neurogenesis and functional plasticity in neuronal circuits. Nat. Rev. Neurosci. 2006, 7, 179-193. [CrossRef] [PubMed]

16. Fuccillo, M.; Joyner, A.L.; Fishell, G. Morphogen to mitogen: The multiple role of hedgehog signaling in vertebrate neural development. Nat. Rev. Neurosci. 2006, 7, 772-783. [CrossRef] [PubMed]

17. Han, Y.G.; Spassky, N.; Romaguera-Ros, M.; Garcia-Verdugo, J.M.; Aguilar, A.; Schneider-Maunoury, S.; Alvarez-Buylla, A. Hedgehog signaling and primary cilia are required for the formation of adult neural stem cells. Nat. Neurosci. 2008, 11, 277-284. [CrossRef] [PubMed]

18. Palma, V.; Lim, D.A.; Dahmane, N.; Sánchez, P.; Brionne, T.C.; Herzberg, C.D.; Gitton, Y.; Carleton, A.; Alvarez-Buylla, A.; Ruiz i Altaba, A. Sonic hedgehog controls stem cell behavior in the postnatal and adult brain. Development 2005, 132, 335-344. [CrossRef] [PubMed]

19. Gulino, R.; Gulisano, M. Involvement of brain-derived neurotrophic factor and sonic hedgehog in the spinal cord plasticity after neurotoxic partial removal of lumbar motoneurons. Neurosci. Res. 2012, 73, 238-247. [CrossRef] [PubMed]

20. Gulino, R.; Gulisano, M. Noggin and sonic hedgehog are involved in compensatory changes within the motoneuron-depleted mouse spinal cord. J. Neurol. Sci. 2013, 332, 102-109. [CrossRef] [PubMed]

21. Gulino, R.; Parenti, R.; Gulisano, M. Novel mechanisms of spinal cord plasticity in a mouse model of motoneuron disease. Biomed. Res. Int. 2015, 2015, 654637. [CrossRef] [PubMed]

22. Buratti, E.; Baralle, F.E. Multiple roles of TDP-43 in gene expression, splicing regulation, and human disease. Front. Biosci. 2008, 13, 867-878. [CrossRef] [PubMed]

23. Cohen, T.J.; Lee, V.M.Y.; Trojanowski, J.Q. TDP-43 functions and pathogenic mechanisms implicated in TDP-43 proteinopathies. Trends Mol. Med. 2011, 17, 659-667. [CrossRef] [PubMed]

24. Strong, M.J.; Volkening, K.; Hammond, R.; Yang, W.; Strong, W.; Leystra-Lantz, C.; Shoesmith, C. TDP-43 is a human low molecular weight neurofilament (hNFL) mRNA-binding protein. Mol. Cell. Neurosci. 2007, 35, 320-327. [CrossRef] [PubMed]

25. Arai, T.; Hasegawa, M.; Akiyama, H.; Ikeda, K.; Nonaka, T.; Mori, H.; Mann, D.; Tsuchiya, K.; Yoshida, M.; Hashizume, Y.; et al. TDP-43 is a component of ubiquitin-positive tau-negative inclusions in frontotemporal lobar degeneration and amyotrophic lateral sclerosis. Biochem. Biophys. Res. Commun. 2006, 351, 602-611. [CrossRef] [PubMed]

26. Bigio, E.H. TAR DNA-binding protein-43 in amyotrophic lateral sclerosis, frontotemporal lobar degeneration, and Alzheimer disease. Acta Neuropathol. 2008, 116, 135-140. [CrossRef] [PubMed]

27. Aizawa, H.; Sawada, J.; Hideyama, T.; Yamashita, T.; Katayama, T.; Hasebe, N.; Kimura, T.; Yahara, O.; Kwak, S. TDP-43 pathology in sporadic ALS occurs in motor neurons lacking the RNA editing enzyme ADAR2. Acta Neuropathol. 2010, 120, 75-84. [CrossRef] [PubMed]

28. Feiguin, F.; Godena, V.K.; Romano, G.; D'Ambrogio, A.; Klima, R.; Baralle, F.E. Depletion of TDP-43 affects Drosophila motoneurons terminal synapsis and locomotor behavior. FEBS Lett. 2009, 583, 1586-1592. [CrossRef] [PubMed]

29. Hideyama, T.; Kwak, S. When does ALS start? ADAR2-GluA2 hypothesis for the etiology of sporadic ALS. Front. Mol. Neurosci. 2011, 4, 33. [CrossRef] [PubMed]

30. Wang, I.F.; Wu, L.S.; Chang, H.Y.; Shen, C.K. TDP-43, the signature protein of FTLD-U, is a neuronal activity-responsive factor. J. Neurochem. 2008, 105, 797-806. [CrossRef] [PubMed]

31. Liu-Yesucevitz, L.; Bassell, G.J.; Gitler, A.D.; Hart, A.C.; Klann, E.; Richter, J.D.; Warren, S.T.; Wolozin, B. Local RNA translation at the synapse and in disease. J. Neurosci. 2011, 31, 16086-16093. [CrossRef] [PubMed]

32. Godena, V.K.; Romano, G.; Romano, M.; Appocher, C.; Klima, R.; Buratti, E.; Baralle, F.E.; Feiguin, F. TDP-43 regulates Drosophila neuromuscular junctions growth by modulating Futsch/MAP1B levels and synaptic microtubules organization. PLoS ONE 2011, 6, e17808. [CrossRef] [PubMed] 
33. Estes, P.S.; Daniel, S.G.; McCallum, A.P.; Boehringer, A.V.; Sukhina, A.S.; Zwick, R.A.; Zarnescu, D.C. Motor neurons and glia exhibit specific individualized responses to TDP-43 expression in a Drosophila model of amyotrophic lateral sclerosis. Dis. Models Mech. 2013, 6, 721-733. [CrossRef] [PubMed]

34. Gulino, R.; Forte, S.; Parenti, R.; Gulisano, M. TDP-43 as a modulator of synaptic plasticity in a mouse model of spinal motoneuron degeneration. CNS Neurol. Disord. Drug Targets 2015, 14, 55-60. [CrossRef] [PubMed]

35. Phelps, P.E.; Barber, R.P.; Houser, C.R.; Crawford, G.D.; Salvaterra, P.M.; Vaughn, J.E. Postnatal development of neurons containing choline acetyltransferase in rat spinal cord: An immunocytochemical study. J. Compos. Neurol. 1984, 229, 347-361. [CrossRef] [PubMed]

36. Gulino, R.; Cataudella, T.; Casamenti, F.; Pepeu, G.; Stanzani, S.; Leanza, G. Acetylcholine release from fetal tissue homotopically grafted to the motoneuron-depleted lumbar spinal cord. An in vivo microdialysis study in the awake rat. Exp. Neurol. 2007, 204, 326-338. [CrossRef] [PubMed]

37. Greengard, P.; Valtorta, F.; Czernik, A.J.; Benfenati, F. Synaptic vesicle phosphoproteins and regulation of synaptic function. Science 1993, 780-785. [CrossRef]

38. Hilfiker, S.; Pieribone, V.A.; Czernik, A.J.; Kao, H.; Augustine, G.J.; Greengard, P. Synapsins as regulators of neurotransmitter release. Philos. Trans. R. Soc. Lond. B 1999, 354, 269-279. [CrossRef] [PubMed]

39. Turner, K.M.; Burgoyne, R.D.; Morgan, A. Protein phosphorylation and the regulation of synaptic membrane traffic. Trends Neurosci. 1999, 22, 459-464. [CrossRef]

40. Ying, Z.; Roy, R.R.; Edgerton, V.R.; Gómez-Pinilla, F. Exercise restores levels of neurotrophins and synaptic plasticity following spinal cord injury. Exp. Neurol. 2005, 193, 411-419. [CrossRef] [PubMed]

41. Bassani, S.; Valnegri, P.; Beretta, F.; Passafaro, M. The GLUR2 subunit of AMPA receptors: Synaptic role. Neuroscience 2009, 158, 55-61. [CrossRef] [PubMed]

42. Isaac, J.T.R.; Ashby, M.; McBain, C.J. The role of the GluR2 subunit in AMPA receptor function and synaptic plasticity. Neuron 2007, 54, 859-871. [CrossRef] [PubMed]

43. Kawahara, Y.; Ito, K.; Sun, H.; Aizawa, H.; Kanazawa, I.; Kwak, S. Glutamate receptors: RNA editing and death of motor neurons. Nature 2004, 427, 801. [CrossRef] [PubMed]

44. Mitchell, N.; Petralia, R.S.; Currier, D.G.; Wang, Y.X.; Kim, A.; Mattson, M.P.; Yao, P.J. Sonic hedgehog regulates presynaptic terminal size, ultrastructural and function in hippocampal neurons. J. Cell Sci. 2012, 125, 4207-4213. [CrossRef] [PubMed]

45. Fawcett, J.W.; Asher, R.A. The glial scar and central nervous system repair. Brain Res. Bull. 1999, 49, 377-391. [CrossRef]

46. Raivich, G.; Bohatschek, M.; Kloss, C.U.; Werner, A.; Jones, L.L.; Kreutzberg, G.W. Neuroglial activation repertoire in the injured brain: Graded response, molecular machanisms and cues to physiological function. Brain Res. Rev. 1999, 30, 77-105. [CrossRef]

47. McGoldrick, P.; Joyce, P.I.; Fisher, E.M.; Greensmith, L. Rodent models of amyotrophic lateral sclerosis. Biochim. Biophys. Acta 2013, 1832, 1421-1436. [CrossRef] [PubMed]

48. Tsao, W.; Jeong, Y.H.; Lin, S.; Ling, J.; Price, D.L.; Chiang, P.M.; Wong, P.C. Rodent models of TDP-43: Recent advances. Brain Res. 2012, 1462, 26-39. [CrossRef] [PubMed]

(C) 2017 by the authors. Licensee MDPI, Basel, Switzerland. This article is an open access article distributed under the terms and conditions of the Creative Commons Attribution (CC BY) license (http://creativecommons.org/licenses/by/4.0/). 